Masanga Medical Research Unit

Masanga Hospital, PO box - 44 Magburaka

Tonkolili district, Sierra Leone

E-mail: m.j.gortzak@amc.uva.nl and m.p.grobusch@amc.uva.nl (Cc)

\title{
Decision Letter
}

MMRU Scientific Review Committee

\begin{tabular}{l|c}
\multicolumn{2}{l}{ General information } \\
\hline Principal Investigator (PI) & Professor Martin P Grobusch \\
\hline Corresponding Investigator & 07-06-2021 \\
\hline Date of submission & $\begin{array}{c}\text { DEntaL Abscess studY (DELAY): Prospective } \\
\text { observational cohort study of complicated odontogenic } \\
\text { infections in two district hospitals in Tonkolili District, } \\
\text { Sierra Leone }\end{array}$ \\
\hline Proposal title & \begin{tabular}{c} 
DELAY \\
\hline Acronym
\end{tabular} \\
\hline SRC number & MMRU-SRC-002-2021 \\
\hline
\end{tabular}

\begin{tabular}{l|c} 
Overall assessment & Score (OK, n/a, clarification required) \\
\hline Scientific quality & OK \\
\hline Scientific interest & OK \\
\hline Ethical considerations & OK \\
\hline Project feasibility & OK \\
\hline Relationship to MMRU research policy & OK \\
\hline Relationship to national research policy & OK \\
\hline Other issues & n/a \\
\hline
\end{tabular}
Decision
$\square$ Accepted without remarks 
X Accepted with remarks*

$\square$ Resubmission following revision

$\square$ Rejected

\section{*Remarks:}

Nice proposal, very necessary to pay more attention to odontological infections in SL. Ambitious project with many objectives. Two brief questions/remarks:

-How will be the WBC performed? Manually or with an automatic cell-counter? If possible, I would advice to also perform a differential WBC (especially if this is not manually performed).

-How will be the pus swab taken? And how will it be stored till and during the shipment?

A proposal that I'm very happy to read. I have treated many severe cases of Ludwig angina and necrotizing fasciitis in my years in Masanga, and for me they have always been amongst the worst and challenging patients I have treated. So, definitely happy to see this moving forward.

\section{Some comments;}

- are there local treatment guidelines?

- date of surgery collect also which surgery was done, just incision and drainage, tooth extraction, (repetitive) debridement and/or possible split skin grafting

- after discharge collect 'skingrafted/not grafted', 'duration of hospitalization'.

- at follow up: measurement of mouth opening, since tooth extraction may only be possible in a postponed setting and not at initial treatment of the odontological abscess/infection they present at first with. However it remains the root of the problem but may initially be inaccesible and poses a possible cause of future deterioration.

Amsterdam, 16-06-2021

\section{Place/Date}




\section{Cllastiu Yvidunef}

Signature

MP Grobusch, SRC Chair and Director, MMRU 